\title{
Multimedia improves knowledge and choice of contraception among pregnant women
}

\author{
Eka Nur Rahayu', C. Asri Budiningsih ${ }^{2}$, B. M. Wara Kushartati ${ }^{3}$ \\ ${ }^{1}$ AKBIDYO College of Health Sciences, Indonesia \\ ${ }^{2,3}$ Yogyakarta State University, Indonesia
}

\begin{tabular}{l}
\hline Article Info \\
\hline Article history: \\
Received May 5, 2020 \\
Revised Jun 7, 2020 \\
Accepted Jul 6, 2020 \\
\hline
\end{tabular}

\begin{abstract}
The quantitative research employed quasi-experimental research with one pretest-posttest group was done to examine the knowledge of pregnant women about family planning and the choosing of contraception. The sample of this study was 41 pregnant women recruited by incidental sampling techniques. Questionnaires for pregnant women provide maternal identity, questions for knowledge about family planning, and the choice of contraception chosen. Data analysis used Wilcoxon test. Multimedia improves the knowledge and choice of contraception among pregnant women.
\end{abstract}

Keywords:

Contraception

Family planning

Health education

Multimedia

Pregnant mother

This is an open access article under the CC BY-SA license.

\section{Corresponding Author:}

Eka Nur Rahayu,

AKBIDYO College of Health Sciences,

Jl. Parangtritis KM 6, Sewon, Bantul, Yogyakarta, Indonesia.

Email: ekanurakbidyo@gmail.com

\section{INTRODUCTION}

The family planning program is an effort to prevent maternal deaths, with these mothers not being pregnant or planning a pregnancy properly [1]. Couples of childbearing age who became active family planning participants in 2018 were $63.27 \%$, while the target was $66 \%$. The low use of the long-term contraception method (MKJP) due to the low public knowledge about the advantages of the MKJP method [2]. A limited number of workers and existing facilities as causes [3]. Knowledge of age couples about contraception is still very low related to counseling services without information from health workers. The correct selection and use of contraception will continue to use contraception. The quality of service and counseling can influence the ongoing use of contraception $[4,5]$. To remove barriers to the use of contraceptive methods is to strengthen the counseling approach to overcome the fear of side effects, promote information, education and communication (IEC) and provide the availability of methods that suit your needs [6].

Factors that influence contraceptive use are partner factors which include age, parity, lifestyle, frequency of sexual relations, family planning, contraceptive experience, femininity, and virility. Health factors are health status, publications, family history, and examination results. Add side effects, side effects, losses, and costs [7, 8]. Policy changes that govern change strategies in public health, where economic and environmental factors influence health behavior. Acceptance of a broader lifestyle, information transfer is directed at the knowledge, attitudes, and behavior of individuals [9].

Family planning (FP) counseling during pregnancy has an important relationship in knowledge so they need 2 years or more to prepare themselves again and involve their husbands which is an effective strategy for getting pregnant [10]. Current counseling relationships increase the compatibility of postpartum 
mothers to use contraception [11]. Provision of contraception with accuracy in the selection of contraception [12]. In the USA results of a review of one study that mentions audiovisual aids are better than oral presentations. The more senses used to receive messages, the clearer they will be obtained [13]. FP counseling using video can improve the work of the right brain because visualization of images, colors, movements, and sounds, it creates a longer memory of the information conveyed, effective use of video is used as a FP counseling media that can help increase knowledge and selection of MKJP [14]. The purpose of this research is how the effectiveness of multimedia-assisted family planning/IEC health education by midwives in helping the selection of contraceptives for pregnant women in Clinic Larashati and laboratory of AKBIDYO College of Health Sciences?.

\section{RESEARCH METHOD}

\subsection{Setting and research design}

This research employed pre-experimental research design of one group pretest-posttest design. It is looking at the knowledge of pregnant women about family planning before and after IEC and knowing the selection of contraceptives before and after IEC using multimedia. The media are PowerPoint presentation and also video of various contraceptive methods modern use a laptop for every pregnant woman once. This research was conducted in the mother and child laboratory of AKBIDYO College of Health Sciences and Larashati Sewon Bantul Yogyakarta clinic in August 2018 because in that region the number of unmet need is high. The sample for this study was pregnant women trimester III in the mother and child laboratory of AKBIDYO College of Health Sciences and Clinic Larashati and as many as 42 pregnant women. The research sample was taken incidentally third-trimester pregnant women examined antenatal care at the time of the study.

\subsection{Instrument and analysis}

Questionnaires for pregnant women contain maternal identity, questions for knowledge about family planning, and the choice of contraception chosen. Knowledge questionnaire This questionnaire was adapted from previous research in the form of correct and wrong as many as 20 questions containing the notion of birth control, the purpose of birth control, various hormonal methods, non-hormones, and side effects and which can't use. The choice of contraception is the chosen method, namely: condoms, pills, injections, IUDs, implants, vasectomy, tubectomy, and others. Research data were collected by midwives who met directly with pregnant female patients, filled out consent, and filled out questionnaires about knowledge and contraception choice plans in the registration room. Pregnant women undergo prenatal care according to the procedure, after completion the midwife provides health education/IEC about family planning using a laptop that already contains material about modern contraceptive methods in the examination room. After completing health education/IEC, a post-test questionnaire was given in the waiting room. Check the questionnaire to make sure everything has been filled out. After the questionnaire was collected, data analysis was performed to test using two related test samples using a Wilcoxon error rate of $5 \%$.

\section{RESULTS AND DISCUSSION}

The number of respondents in this study was 41 third trimester pregnant women with characteristics as shown in Table 1 . The results of Table 1 show that the characteristics of pregnant women for healthy reproductive mothers are $73.2 \%$ and $24.4 \%$ of those over 35 years. The mother's education is $61.0 \%$ high school and $22.0 \%$ junior high school. Housewife is counted as much as $68.3 \%$. Second maternal pregnancy is counted as much as $41.5 \%$ and first pregnancy $39.0 \%$. Women who have never had birth control are $56.1 \%$ and $24.4 \%$ have used injections. Information from health workers about family planning was obtained by mothers as much as $63.4 \%$ and most from mothers who had given birth or used contraception before. Pregnant women who have a history of most diseases are asthma as many as four people and the others are hyperthyroidism one person, fibroma mammary adenoma (FAM) one person, and anaemia one person. Pregnant women who have a history of most diseases who have received information know that they should not use certain contraceptives.

Knowledge of pregnant women has increased before IEC was carried out and after IEC was given. This can be seen from Figure 1. The results Figure 1 showed that for the knowledge of pregnant women before health education the cut off value was 40 and the highest value was 90 . After having done health education the lowest value increased to 60 and the highest was 95 . After 81.5 mothers who have received information about family planning from health workers have prior knowledge and are getting better after getting health education. The education of pregnant women in elementary school has lower knowledge compared to high school education and the education of bachelor's degree mothers has knowledge with a value of more than 80 . For many mothers who know more about condoms for men and women, use contraception for mothers and side care methods IUD contraception and male operating methods. 
Table 1. Characteristics of trimester III pregnant women

\begin{tabular}{lcc}
\hline \multicolumn{1}{c}{ Characteristics } & Frequency & Percent (\%) \\
\hline Age & 1 & 2.4 \\
<20 years & 30 & 73.2 \\
20-35 years & 10 & 24.4 \\
>35 years & & \\
Education & 4 & 9.8 \\
$\quad$ Primary school & 9 & 22.0 \\
Junior high school & 25 & 61.0 \\
Senior high school & 3 & 7.3 \\
Bachelor degree & & \\
Pregnancy & 16 & 39.0 \\
1 & 17 & 41.5 \\
2 & 5 & 12.2 \\
3 & 1 & 2.4 \\
4 & 2 & 4.9 \\
5 & & \\
FP history & 23 & 56.1 \\
Never & 1 & 2.4 \\
Natural & 2 & 4.9 \\
Condoms & 4 & 9.8 \\
Pill & 10 & 24.4 \\
Injections & 1 & 2.4 \\
IUD & & \\
FP information from health workers & 26 & 63.4 \\
Yes & 15 & 36.6 \\
No & & \\
Disease history & 8 & 19.5 \\
Yes & 33 & 80.5 \\
No & 41 & 100.0 \\
Total & & \\
\hline & & \\
\hline & &
\end{tabular}

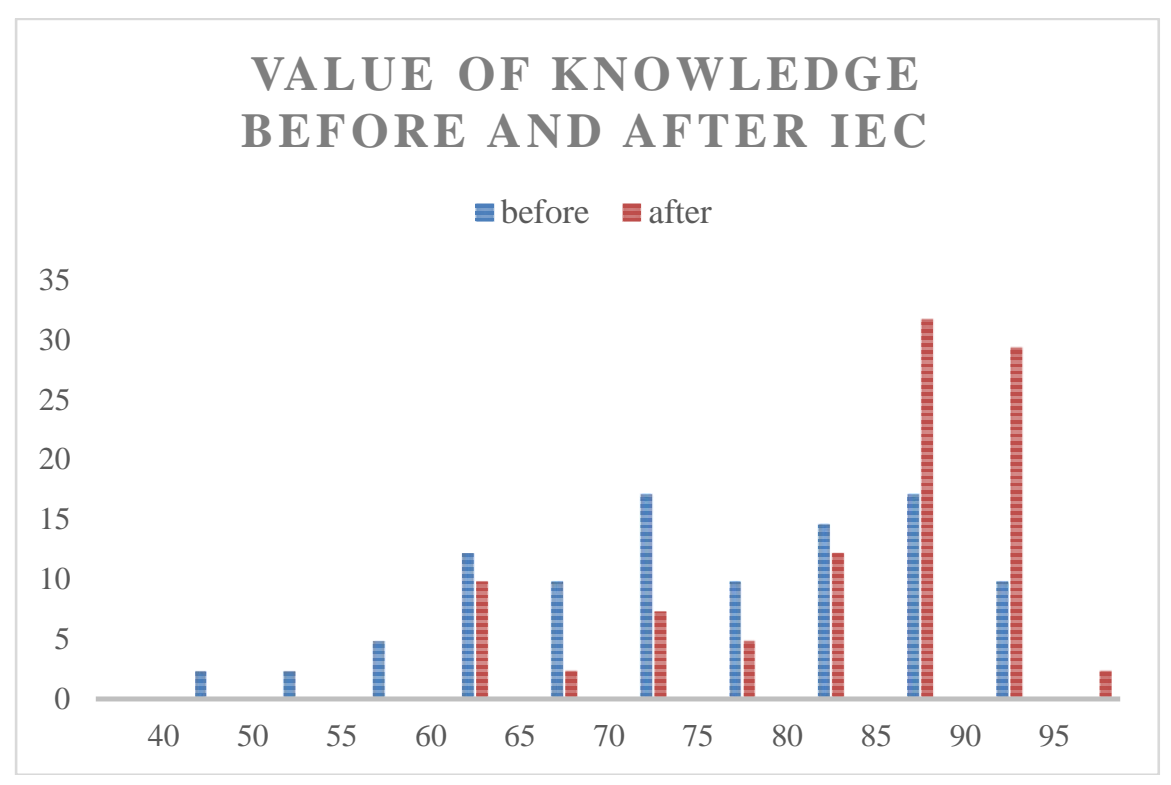

Figure 1. Knowledge of pregnant women before and after health education

The choice of contraception for pregnant women has changed to better contraception after IEC, can be seen in Figure 2. From the Figure 2 above, it can be seen that pregnant women who did not want to use contraception before, want to use modern contraception in women who have good knowledge about contraception. The results of data analysis using Wilcoxon 95\% confidence level of contraceptive selection showed there were differences before and after health education was given with a $\mathrm{Z}$ value of $-3.360 \mathrm{p}<0.05(0.001)$. The choice of contraception that had not yet used or used natural methods as many as 15 mothers shifted to the selection of modern contraceptives such as pills, injections, IUDs, and tubectomy and those that remained with the election as before there were 26 mothers. Knowledge of pregnant women has a difference 
before and after health education is given with a calculated $\mathrm{Z}$ value of $-3.843 \mathrm{p}<0.05(0.000)$. The knowledge of pregnant women about family planning increased by an average of 8.7, i.e knowledge with a mean before education was 72.8 and the average after getting health education was 81.5. The knowledge of pregnant women after being given education about contraception decreased by 4 mothers, the knowledge of which remained 8 mothers and that experienced an increase of 29 mothers. Figure 2 shows that pregnant women who did not want to use contraception before, want to use modern contraception in women who have good knowledge about contraception. The Wilcoxon test result is shown in Table 2.

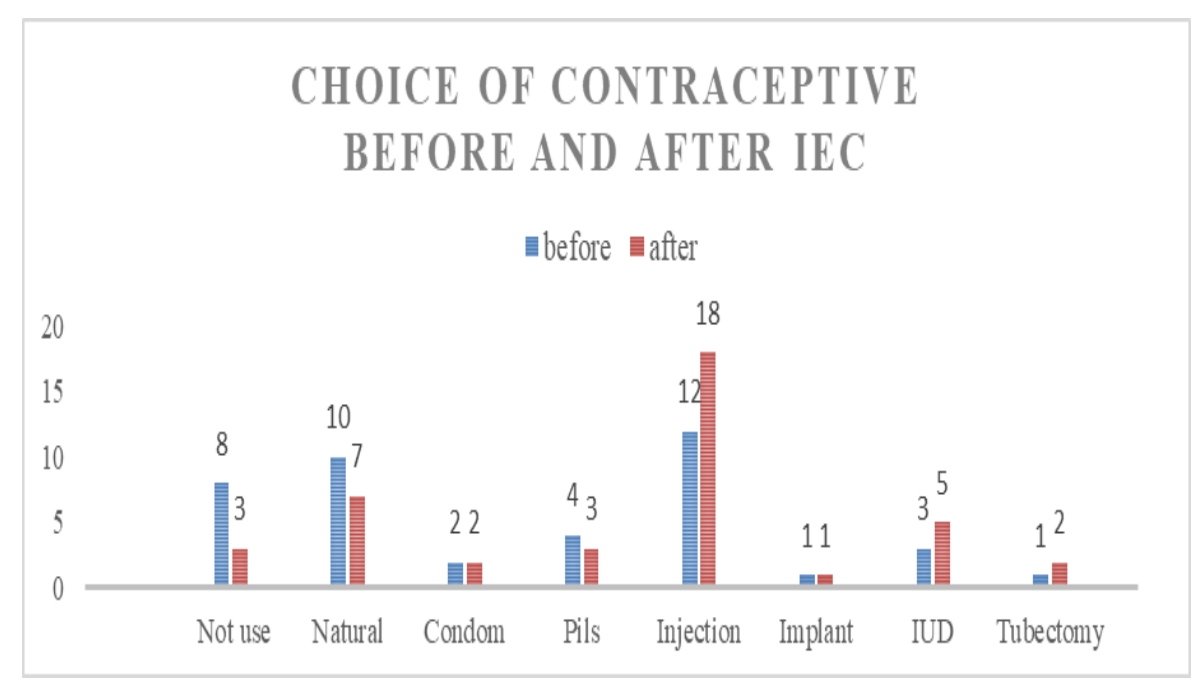

Figure 2. Selection of contraception before and after the provision of health education

Table 2. Analysis of the selection and knowledge of pregnant women before and after

\begin{tabular}{|c|c|c|c|}
\hline & $\mathrm{N}$ & Mean Rank & Sum of Ranks \\
\hline \multicolumn{4}{|l|}{ Selection after-selection before } \\
\hline Negative Ranks & $0^{\mathrm{a}}$ & .00 & .00 \\
\hline Positive Ranks & $15 b$ & 8.00 & 120.00 \\
\hline Ties & $26^{\mathrm{c}}$ & & \\
\hline \multicolumn{4}{|l|}{ Value after-Value before } \\
\hline Negative Ranks & $4^{\mathrm{d}}$ & 16.63 & 66.50 \\
\hline Positive Ranks & $29^{\mathrm{e}}$ & 17.05 & 494.50 \\
\hline Ties & $8 \mathrm{f}$ & & \\
\hline Total & 41 & & \\
\hline \multicolumn{4}{|l|}{ Selection after-selection before } \\
\hline $\mathrm{Z}$ & -3.468 & & \\
\hline Asymp. Sig. (2-tailed) & .001 & & \\
\hline \multicolumn{4}{|l|}{ Value after-Value before } \\
\hline $\mathrm{Z}$ & -3.843 & & \\
\hline Asymp. Sig. (2-tailed) & .000 & & \\
\hline \multicolumn{4}{|l|}{ a. Selection after $<$ selection before } \\
\hline \multicolumn{4}{|l|}{ b. Selection after>selection before } \\
\hline \multicolumn{4}{|l|}{ c. Selection after=selection before } \\
\hline \multicolumn{4}{|l|}{ d. Value after $<$ Value before } \\
\hline \multicolumn{4}{|l|}{ e. Value after $>$ Value before } \\
\hline f. Value after $=$ Value before & & & \\
\hline
\end{tabular}

The results show that there were differences in selection and knowledge after health education about family planning. There was a significant difference in mothers' knowledge about family planning before and after being given health education/IEC with a p-value $<0.05$. The value of knowledge prior to health education is the lowest 40 , the highest is 90 and after the health education is given the lowest value is 60 , the highest is 95 , there is an increase in the value of 20 for the lowest value and an increase of 5 points for the highest value. The average increase in knowledge before and after was 8.7.

The results showed there was a difference between selection and knowledge after health education about family planning. There are differences in mothers' knowledge about family planning before and being 
given health education/IEC. Knowledge of pregnant women who have received information about family planning about health workers must know more about those who have never been able to get information $[15,16]$. The use of multimedia in the field of education greatly helps the knowledge of mothers. Multimedia can present information that can be seen, heard, and carried out very effectively, multi-sensory and a good retention rate thereby increasing the quality of information delivery, interactive [17]. Various educational tools can enhance client knowledge and provide assistance to clients in the decision-making process or development of contraceptive methods [18]. The use of Smart Choice multimedia as a tool is very useful and needs to be developed for family planning counseling [19]. Using video to provide information from four groups, from the initial choice of using condoms, $80 \%$ shifted to injecting and pill use. The effectiveness of contraceptives is the main consideration in the selection [20]. Audiovisual aids work better than normal oral percentages by doctors. A good counseling program causes more women to choose the method of structuring or modern contraceptive methods [21]. Decision support tools DST contraception can increase positively for patient services, increase joint decision making between patients and officers in counseling. DST reduces bias and meets patient needs because there is writing or visuals [22]. Small, happy, and prosperous families in Ethiopia (SHaPE) one of Ethiopia's first approved multimedia campaigns that support family planning to improve knowledge, attitudes, and practices related to family planning in Ethiopia, specifically for women who receive payments [23]. Video can be an attractive alternative media for family planning that is interesting and easily captured by prospective acceptors. The use of effective video is used as a family planning counseling media that can help increase MKJP knowledge and selection [14]. The addition of experimental illustration images to multimedia and the use of more communicative language can help in determining work procedures [24]. Audiovisual media has a significant role in increasing knowledge [25]. A computer-aided motivational interview helps women to start using contraception [26]. Development of tablet-based contraceptive decision-support devices designed to facilitate client decision making. The results of the evaluation are better with tablet use, including higher satisfaction with the choice of method and an increase in knowledge about the method [27]. Formally supporting tablet-based contraceptive decision support designed to facilitate decision making between clients and officers, ultimately supporting clients in choosing the contraceptive method that best suits client preferences [28].

Mother's knowledge is also influenced by education, by seeing that higher education, namely high school and bachelor, has improved knowledge about family planning. Mothers who have elementary education still have the lowest knowledge after being given education, despite an increase. Mothers who have used contraception before having better knowledge than mothers who have never used contraception. There is a significant relationship between family planning counseling during pregnancy and high maternal education using more contraception after giving birth. Counseling during pregnancy can increase the effectiveness of the mother during childbirth to use contraception, [8, 10-12, 29, 30].

There are significant differences in the selection of contraceptives before and after being given health education/IEC. Previously, pregnant women who did not want to use birth control and used natural birth control shifted to choosing modern birth control such as pills, injections, IUDs, and tubectomy. High knowledge of pregnant women tends to choose modern contraception such as injection, IUD, implant, and tubectomy. Women who receive counseling tend to use effective contraception. This study supports that health professionals must provide services at every opportunity during pregnancy, childbirth, and childbirth to provide information and counseling to increase knowledge and awareness of contraception [31]. Contraceptive counseling given by doctors results in $50 \%$ of women needs contraceptive counseling at the time of the visit and those who receive contraceptive counseling from providers experience increased use of hormonal contraception. Contraceptive counseling in primary care makes it possible to reduce unwanted pregnancies [32]. After being given counseling their knowledge is good and raises greater curiosity. Higher education influences their knowledge about contraception [12]. The quality of counseling services has a positive impact on family planning decisions. Service quality contributes high to increasing participation in family planning programs [29]. An additional counseling program in our study in addition to standard practice has a moderate impact on contraceptive use and effective use of contraception in postpartum women in Spain [33].

The number of children influences the choice of contraception, where mothers who have more than two children choose long-term modern contraception such as injection, IUD, implant, and tubectomy. While mothers who are pregnant for the first time and have never used contraception choose not to use or use natural methods, condoms, pills, and injections. Other factors that might influence the choice of contraception are education, number of children, age, marital status, desire to get pregnant again [34].

Mothers who have a history of illness want to use natural methods or condoms. Factors influencing acceptors in choosing a contraceptive method are among other factors the couple experiences with the previous contraceptive method, health factors. In addition to these factors, another factor influencing the choice of contraception is the difficulty of controlling health [35]. Factors that influence the choice of contraception using past contraception, health status, complexity, complexity, minor side effects, 
complications [7]. The choice of an individual or partner contraceptive method considers using contraception with various factors to assess the society of women if she can provide children to their partners [36]. The quality of contraceptive counseling as one of the strategies that must be avoided. Identification of relations and communication aspects of family planning tasks with officers and client needs [37].

Providing health education/IEC FP use multimedia helps with the choice of contraception for pregnant women. Differences in the knowledge of pregnant women about contraception before and given health education/IEC increase in knowledge FP with an average value of 8.7. There are differences in the choice of contraception before and after being given health education/IEC using multimedia.

\section{CONCLUSION}

Midwive and other health practitioners have to improve the quality of health education services (IEC, counseling) of family planning using multimedia aids. It should be starting from pregnancy so that mothers can choose the right contraception after they are postpartum. Patient knowledge is one of the factors that influence the choice of contraception. Patients can increase knowledge about contraception while still pregnant with health workers so that they can help in choosing contraception immediately after giving birth. It is necessary to develop multimedia that is more practical and effective for counseling contraceptive for app-based health workers.

\section{ACKNOWLEDGEMENTS}

Thank you to AKBIDYO High School of Health Sciences for supporting this research.

\section{REFERENCES}

[1] Labola, Yostan Absalom, "The role of family planning in reducing maternal and newborn deaths in Indonesia, Satya Wacana Christian University, ResearchGate, 2018.

[2] BKKBN, "2015 BKKBN Government Agency Performance Report,” Jakarta Indonesia, 2016. [Online]. Available: https://www.bkkbn.go.id/po-content/uploads/Final_lakip_bkkbn_2016.pdf

[3] "The Indonesian Ministry of Health,” Indonesia Health Profile 2018. Jakarta Indonesia: Ministry of Health Republic of Indonesia, 2019. [Online]. Available: https://www.kemkes.go.id/resources/download/pusdatin/profilkesehatan-indonesia/profil-kesehatan-indonesia-2018.pdf

[4] A. Alem, Gebremariam, Adamu, "Knowledge and Perception on Long Acting and Pemanent Contracetive Methods in Adigrat Town tigray Northern Ethiopa: A Qualitative study," International Journal of Family Medicine, vol. 2014, 2014.

[5] J. Rokhmah, "Evaluation of the use of decision making aids (ABPK) in family planning services by Puskesmas midwives in Cirebon City," Thesis, Universitas Diponegoro, 2014.

[6] D. Herowati, D. Listyawardani, and T. Y. Prihyugiarto, "Unmet Need and its Reasons for Nonuse Contraceptive in East Java Province," International Journal of Public Health Science (IJPHS), vol. 5, no. 3, pp. 313-319, 2016.

[7] H. Hartanto, "Family Planning and Contraception. Jakarta," Indonesia: Pustaka Sinar Harapan, Jakarta, 2013.

[8] Y. M. Kim, D. Odallo, and M. Thuo, "Client Participation and Provider Communication in Family Planning Counseling: Transcript Analysis in Kenya," Health Communication, vol. 11, no. 1, pp. 1-19, 1999.

[9] Lawrence W. Green, "Modifying and developing health behavior," in Annual Review of Public Health, vol. 5, pp. 215-236, 1984.

[10] P. Chinnakali, Jyotsna sharma, Gowri Dorairajan, "Knowledge and Attitude towards contraceptive methods for spacing and decison making factor regrading its use in postpartum women," International Journal of Reproduction Contraception, Obstetrics and Gynecology, vol. 4, no. 3, pp. 750-754, 2015.

[11] J. Pooler, Leticia E. Hernandez, William M. Sappenfield, David Goodman, "Is Effective Contraception Use Conceived Prenatal in Florida? The Association between Prenatal Contraceptive Counseling and Postpartum Contraceptive Use," Maternal and Child Health Journal, vol. 16, no. 2, pp. 423-429, 2011.

[12] Sandrinilta, "The relationship of providing counseling to family planning acceptors to the accuracy of the selection of contraceptives at the Tegalrejo Public Health Center in Yogyakarta," Aisyiyah College of Health Sciences Yogyakarta, 2015.

[13] L. Laureen M., M. Steiner, G. David A., D. Hilgenberg, and Schulz K. F., "Strategies for communicating contraceptive effectiveness," Conchrane Database of Syastematic Reviews, vol. 30, no. 4, 2013.

[14] K. M. Astri Nurdiana, Firman Wirakusumah, "Development of FP Video-Based Counseling Models," Tunas-Tunas Ris. Kesehat., vol. VI, no. November, 2016. [Online]. Available: http://2trik.jurnalelektronik.com/index.php/2trik/article/view/29

[15] H. M. Schwandt, A. A. Creanga, K. A. Danso, R. M. K. Adanu, T. Agbenyega, and M. J. Hindin, "Group versus individual family planning counseling in Ghana : a randomized, noninferiority trial," Contraception, vol. 88, no. 2 , pp. 281-288, 2013.

[16] E. Purwaningsih, S. Zukhri, and A. Rachmawati, "Pengaruh pemberian konseling terhadap pengetahuan dan minat pengguna kontrasepsi mal di ponet grobogan grobogan jawa tengah,” J. Involusi Kebidanan, vol. 6, no. 11, pp. 16, 2016

[17] Munir, "Multimedia Concepts and Applications in Education," I. Bandung: Alfabeta Bandung, 2012. 
[18] L. B. Zapata, S. J. Tregear, K. M. Curtis, K. Pazol, N. Mautone-smith, and L. E. Gavin, "Impact of Contraceptive Counseling in Clinical Setting: A Systematic Review," American Journal of Preventive Medicine, vol. 49, no. 2, pp. 1-23, 2015.

[19] B. H. P. Koo, E. K. Wilson, and M. Minnis, "A Computerized Family Planning Counseling Aid : A Pilot Study Evaluation of Smart Choices," Perspectives on Sexual and Reproductive Health, vol. 49, no. 1, pp. 45-53, 2017.

[20] L. W. Zhu Jianzhong, yan Ma, "Strategies for Communicating Contraceptive Effectiveness," Public Health Nursing, vol. 31, no. 5, pp. 438-440, 2014.

[21] T. Wilkinson and R. Reinhardt, "Technology in Counselor Education: HIPAA and HITECH as Best Practice," The Professional Counselor, vol. 5, no. 3, pp. 407-418, 2015.

[22] C. Marshall, A. Nuru-jeter, S. Guendelman, J. Mauldon, and T. Raine-bennett, "Patient Education and Counseling Patient perceptions of a decision support tool to assist with young women 's contraceptive choice," Patient Education Counseling, vol. 100, no. 2, pp. 343-348, 2017.

[23] H. Paek et al., "Rationale, design, and characteristics of the multimedia family planning campaign for a small, happy, and prosperous family in Ethiopia (SHaPE)," BMC Public Health, vol. 18, no. 861, pp. 1-9, 2018.

[24] W. Kurniawan, D. Darmaji, A. Astalini, D. A. Kurniawan, and M. Hidayat, "Multimedia physics practicum reflective material based on problem solving for science process skills," International Journal of Evaluation and Research in Education (IJERE), vol. 8, no. 4, pp. 590-595, 2019.

[25] S. N. Djannah, S. Sulistyawati, and T. W. Sukesi, "Audio-visual media to improve sexual-reproduction health knowledge among adolescent," International Journal of Evaluation and Research in Education (IJERE), vol. 9, no. 1, pp. 138-143, 2020.

[26] B. E. Christine, G. C. Jennifer, D. Dora, A. R. S. Lynda, R. Mary, and J. V. D. B. Jacob, "Computer-Assisted Motivational Interviewing for Contraceptive Use in Women Leaving Prison: A Randomized Controlled Trial," Contraception, vol. 101, no. 5, pp. 327-332, 2020.

[27] C. Dehlendorf, C. Krajewski, Sonya B., "Contraceptive Counseling: Best Practices to Ensure Quality Communication and Enable Effective Contraceptive Use," Clinical Obstetrics and Gynecology, vol. 57, no. 4, pp. 659-673, 2014.

[28] M. Chen, A. Lindley, K. Kimport, and C. Dehlendorf, "An in-depth analysis of the use of shared decision making in contraceptive counseling," Contraception, vol. 99, no. 3, pp. 187-191, 2019.

[29] P. P. Ken Sudarti, "Increased Interest and Decision to Participate in FP Acceptors," J. Din. Manaj., vol. 2, no. 2, pp. 130-138, 2011.

[30] S. Ramarao and R. Mohanam, "The Quality of Family Planning Programs : Concepts, Measurements, Interventions, and Effects," Studies in Family Planning, vol. 34, no. 4, pp. 227-248, 2003.

[31] L. Lauria, S. Donati, A. Spinelli, M. Bonciani, and M. E. Grandolfo, "The effect of contraceptive counselling in the pre and post-natal period on contraceptive use at three months after delivery among Italian and immigrant women," Ann Ist Super Sanita, vol. 50, no. 1, pp. 54-61, 2014.

[32] J. K. Lee, S. M. Parisi, A. Y. Akers, S. Borrerro, and E. B. Schwarz, "The Impact of Contraceptive Counseling in Primary Care on Contraceptive Use," Journal of General Internal Medicine, vol. 26, no. 7, pp. 731-736, 2011.

[33] A. Reyes-lacalle, L. Montero-pons, J. M. Manresa-domínguez, R. Cabedo-ferreiro, G. Seguranyes, and G. Falguera-puig, "Perinatal contraceptive counselling: Effectiveness of a reinforcement intervention on top of standard clinical practice," Midwifery, vol. 83, p. 102631, 2020.

[34] B. J. oddens Arie Yeshaya, Amos Ber, Daniel S Seidman, "Influence of Structured counseling on women's selectioan of hormonal contracetion in Israel: results of the CHOICE study," International Journal of Women's Health, vol. 6, pp. 799-808, 2014.

[35] L. kusmiyati Gita Kostania, Kuswati, "Effects of Counseling Using Family Planning Decision Making Tools (ABPK) on the Use of Intra-Uterine Device (IUD) Contraception," KesMaDaSka Juli 2014, pp. 83-89, 2014. [Online]. Available: http://id.portalgaruda.org/?ref=browse\&mod=viewarticle\&article=153482

[36] C. L. Varney, Hellen, Jan M. Kriebs, Gegor, "Midwifery Orphanage Teaching," Edition 4, 4th ed. Jakarta Indonesia, 2007.

[37] S. Borrero, Christine Dehlendorf, Colleen Krajewski, "Contraceptive Counseling: Best Practices to Ensure Quality Communication and Enable Effective Contraception Use," Clinical Obstetrics and Gynecology, vol. 57, no. 4, pp. 659-673, 2015. 